\title{
Models of formation and spread of fire to increase safety of road tunnels
}

\author{
Peter Danisovic ${ }^{1,{ }^{*}}$, Jan Glasa ${ }^{2}$, Peter Weisenpacher ${ }^{2}$, and Lukas Valasek ${ }^{2}$ \\ ${ }^{1}$ University of Zilina, Faculty of Civil Engineering, Univerzitna 8215/1, 01026 Zilina, Slovakia \\ ${ }^{2}$ Institute of Informatics, Slovak Academy of Sciences, Dubravska cesta 9, 84507 Bratislava, Slovakia
}

\begin{abstract}
Fire safety of tunnels is an important issue which must be solved carefully during all phases of preparation, building and operation of each road tunnel. In this paper some particular results of a joint research project of the Institute of Informatics of Slovak Academy of Sciences and the University of Zilina are summarized. Some specific phenomena caused by fire in a real highway tunnel in Slovakia endangering safe evacuation of people from the tunnel are illustrated.
\end{abstract}

\section{Introduction}

Recent large-scale catastrophic events in underground structures such as large car parks and tunnels have caused enormous material damages, led to tragic losses of human lives and endangered important international traffic structures and systems. To prevent devastating consequences of such events a big effort is paid for providing best practices and adopting efficient fire safety procedures in currently prepared, built as well as operated road tunnels.

Tunnel is generally a very complex and robust structure requiring enormous investment costs. Therefore, a high degree of protection is required for each tunnel in operation. However, the increasing number of cars on roads and in transport structures as well as the number of road tunnels in operation cause a growth of car incidents. One of the most destructive events in tunnel is fire of a car or group of cars. Therefore, the interest to investigate possible course of fire and development of smoke produced by fire in each tunnel is increasing. There are different possibilities how to study the course of fire and its consequences. An important form of fire study is to prepare a fire as a full-scale or smallscale experiment with extensive measuring instrumentations. Full-scale experiment is a copy of a fire in real or very similar geometric dimensions. Small-scale experiment is a copy of a fire received by creating reduced geometric dimensions and/or by including some other input variables. Consistent analysis of obtained experimental data often helps to formulate laws and description of combustion products, their range and other fire properties. However, fire experiment in a tunnel in operation is very expensive because it would cause material damages and even lead to the tunnel failure. Moreover, tunnels differ from each other by their shape, spatial dimensions, slope, ventilation, and so on. For this reason, the results of a full-scale fire experiment in one tunnel cannot be automatically applied to another tunnel. The next possibility is to use theoretical laws and the knowledge

*Corresponding author: peter.danisovic@ffstav.uniza.sk 
about formulation of physical modelling of fire which can be used as a test or demonstration of fire in given tunnel utilizing the main advantage of this approach, the flexible use of different distributions of flammable materials in the tunnel and different fire scenarios [1].

To ensure the road tunnel safety in the case of fire, various safety systems are used among which ventilation system is especially important. There are two main computer modelling approaches for the design of a tunnel ventilation system: 1D and CFD (Computational Fluid Dynamics) approaches. The 1D approach for ventilation simulation in tunnels [2] is used to simulate steady-state calculations in a tunnel system with low computational requirements. It can be used to simulate a whole tunnel network including chimneys, main tunnels and branches. However, the key disadvantage is that it is useful for bulk flows, but does not adequately represent flows in complex regions or the couplings between multiple variables, e.g., jet fans, tunnel geometry, traffic, environmental influence, heat, etc. With the increasing size and scale of the complexity of modern tunnels, the 1D method alone is increasingly inadequate to model these complex interactions and couplings [3]. The CFD is a more modern technique [4-7] which has been used over the last two decades focused mainly on refining the numerical methods, and verification and validation of the fire simulation systems. CFD allows better representation of complex regions, however, for a larger variety of quantities to be coupled and modelled it is computationally expensive. Therefore for practicality CFD is currently used to only model a select region of a tunnel ventilation section. In last years, a big effort is paid for analysis of applicability of current high-performance computing systems to allow the modelling of longer tunnel sections or the whole tunnel structure to study the coupling or interaction (e.g., between a tunnel section and a station) [3].

Institute of Informatics of Slovak Academy of Sciences and Centrum of Transport Research of the University of Zilina solve a joint research project focused on the study of models of formation and spread of fire to increase safety of road tunnels to increase their safety. The project research results will be applied by National Highway Company, a. s. (NDS) and PPA Engineering, s.r.o. (PPA). The main aims of the project are to develop:

- a series of computer simulations of selected types of fires in selected road tunnels managed by NDS according to negotiated scenarios using the FDS fire simulation program system

- thorough analysis and visualization of the simulation results

- $\quad$ series of visualizations of results of computer simulation of fires in a virtual tunnel in the Tunnel Traffic \& Operation Simulator (TTOS) at Centrum of Transport Research of the University of Zilina using the FDS system

- database of evidence of incidents in road tunnels in operation in Slovakia with analysis and statistical processing of the data

- actual risk analysis of tunnels in operation and verification of the impact of transport of emergent goods on final value of risk specified by current legislation

and conduct a series of full-scale fire experiments in a single- and two-tube highway tunnel managed by NDS. The project is specifically focused on the smoke stratification investigation and the impact of ventilation on maintaining and disruption of stratification.

This paper summarizes some particular results of the joint research project on computer modelling of flows in specified highway tunnel in Slovakia and illustrates dangerous phenomena caused by fire which endanger safe evacuation of people from the tunnel.

\section{Methodology}

The aim of this paper is to show the results of computer simulation of some specific phenomena arising during tunnel fire using the FDS simulation system. Preparation and 
realization of the simulations in a parallel manner as well as the simulation results processing are not trivial tasks requiring a thorough application of various types of methodologies. The project methodology includes:

- gathering data about geometry of the tunnel where fire will be simulated, fire properties of flammable materials, initial and boundary conditions and other input parameters for simulation of fire according to given scenario

- modelling 3D structures in which fire will be simulated and preparation of input data and simulation parameters

- representation of the place and way of the fire origin

- design of calculation parallelization

- realization of parallel calculation on a high-performance computing system

- simulation results processing and analysis

- creation of visualisations

- $\quad$ validation of fire simulation results by full-scale fire experiments.

Within the project, the related standard methodologies commonly used in the fire modelling community are thoroughly applied.

\subsection{Fire Dynamics Simulator}

Fire Dynamics Simulator (FDS) is a CFD-based simulation system intended for modelling of fire-driven fluid flows developed by the National Institute of Standards and Technology, USA with cooperation with VTT Technical Research Centre of Finland [8,9]. FDS numerically solves a form of Navier-Stokes equations appropriate for the low-speed, thermally-driven flow with an emphasis on the smoke and heat transport from fires. It also includes models of various physical and chemical processes related to fire such as turbulence, thermal radiation, pyrolysis, combustion of the pyrolysis products, conductive heat transfer, fire suppression, etc. FDS enables various kinds of parallelization of calculation utilizing advantages of available computer platforms.

The input data for fire simulation using FDS can be divided into three groups: geometrical data including the size and shape of the tunnel, location, size and shape of all objects in the tunnel; representation of jet fans, data characterizing properties of burning materials (ignition temperature, thermal conductivity, specific heat, density, emissivity, heat of evaporation of unit quantity of material, etc.) and heat release rate (HRR) of fire. The most important output of the gaseous component are usually temperature, velocity, pressure and density of the gas, the concentration of smoke and visibility as well as an estimate of the total HRR [10-13].

\subsection{HPC cluster}

The used high-performance computing cluster (HPC cluster) is located at Institute of Informatics of Slovak Academy of Sciences in Bratislava (Slovakia) [1, 14]. It is a HP blade cluster consisting of 54 compute nodes, each comprising of two 6-core $2.4 \mathrm{GHz}$ processor Intel Xeon X5645 and 48GB of RAM. All nodes are connected by the Infiniband interconnection network with the bandwidth of $40 \mathrm{Gbit} / \mathrm{s}$ per link and direction (see Fig. 1).

\subsection{Tunnel Traffic \& Operation Simulator}

Tunnel Traffic \& Operation Simulator (TTOS) is located at Centrum of Transport Research of the University of Zilina (see Fig. 1) [15-17]. This technology was developed by PPA Engineering s.r.o. in terms of functionality based on real control algorithms used for the 
management of existing tunnels. It allows to simulate incidents which are rare in the real tunnel traffic with the aim of verification of correctness and philosophy of the management. Visualizations of the tunnel management are the same as on the real operator workplace of a two-tube tunnel. In contrast to real traffic, simulation of video surveillance shows a virtual traffic in the tunnel tubes and in front of them. As most of operator workstations also the operator workstation of the simulator is implemented to operate the tunnel by two operators. The first operator is responsible for management of the tunnel traffic system; the second operator is responsible for the management of the tunnel technology equipment. There are changeable; a single operator is able to control the entire tunnel. This simulation workstation for the road tunnel control and operation is realized as a real tunnel control centre of a virtual $1000 \mathrm{~m}$ long two-tube highway tunnel with unidirectional traffic. The technological equipment of the virtual tunnel is in accordance with Slovak legislative regulation. TTOS consists of the central control system (part of automatic tunnel equipment control), manual control module (part of manual control - separated module) and software for prediction of phenomena (EMUT - evidence of tunnel incidents). It can be used for training and education of tunnel specialists as well.
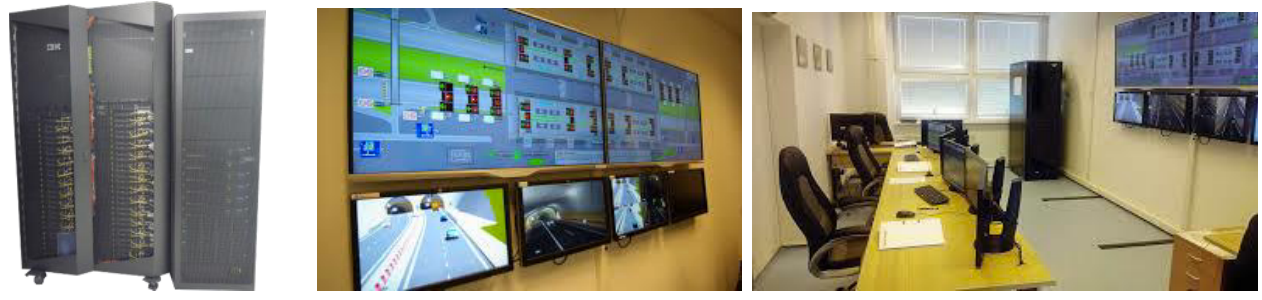

Fig. 1. HPC cluster at Institute and Informatics, Slovak Academy of Sciences (left) and Tunnel Traffic \& Operation Simulator at Centrum of Transport Research, University of Zilina (middle and right).

\section{Road tunnel fire modelling}

Proper jet fan ventilation strategy is a crucial precondition of efficient safety measures in road tunnels. In unidirectional tunnels, the procedure is straightforward: jet fans create an air flow to push the smoke away from the tunnel and to prevent backlayering in upstream direction (so called critical flow velocity). Conditions downstream of the fire are usually untenable for people as critical velocity does not maintain the smoke stratification assuming that people are able to escape before conditions become untenable. In bidirectional tunnels, people are endangered by smoke on both sides of the fire, therefore the tenability conditions $[18,19]$ should be maintained long enough to ensure safe people evacuation. The aim of ventilation is to achieve a prescribed target flow velocity maintaining the smoke stratification (the Slovak and Czech regulations recommend the velocity value of $1.5 \mathrm{~m} / \mathrm{s}$ [20] and $1.2 \mathrm{~m} / \mathrm{s}$ [21], respectively). However, the impact of buoyancy forces created by fire may lead to significantly higher flow velocities in some regions of the tunnel, therefore the smoke stratification may not be maintained there. Therefore, careful evaluation is needed to predict the smoke movement. This problem is of special importance in Slovakia because of increasing number of road tunnels with longitudinal ventilation $[22,23]$. To describe the descent of the smoke layer, entrainment between hot and cold layers [24] is modelled by the entrainment equations $[25,26]$. However, there is a lack of knowledge about their general applicability and they must be validated for each tunnel. Therefore, computer simulation of typical fire and ventilation scenarios can be considered as useful guide for tunnel management. 
In this paper, the impact of ventilation on smoke stratification in the Polana highway tunnel (Slovakia) is illustrated. The Polana tunnel is a $900 \mathrm{~m}$ long single-tube bidirectional highway tunnel with a longitudinal ventilation consisting of four couples of jet fans. We conducted computer simulation of automobile fire in the middle of the tunnel between two emergency lay-bys. The ventilation was set in accordance with Slovak legislation regulations. In Fig. 2, the development of smoke is illustrated in four phases of the fire spread. The figures show the smoke stratification during the first 160 seconds of the fire.

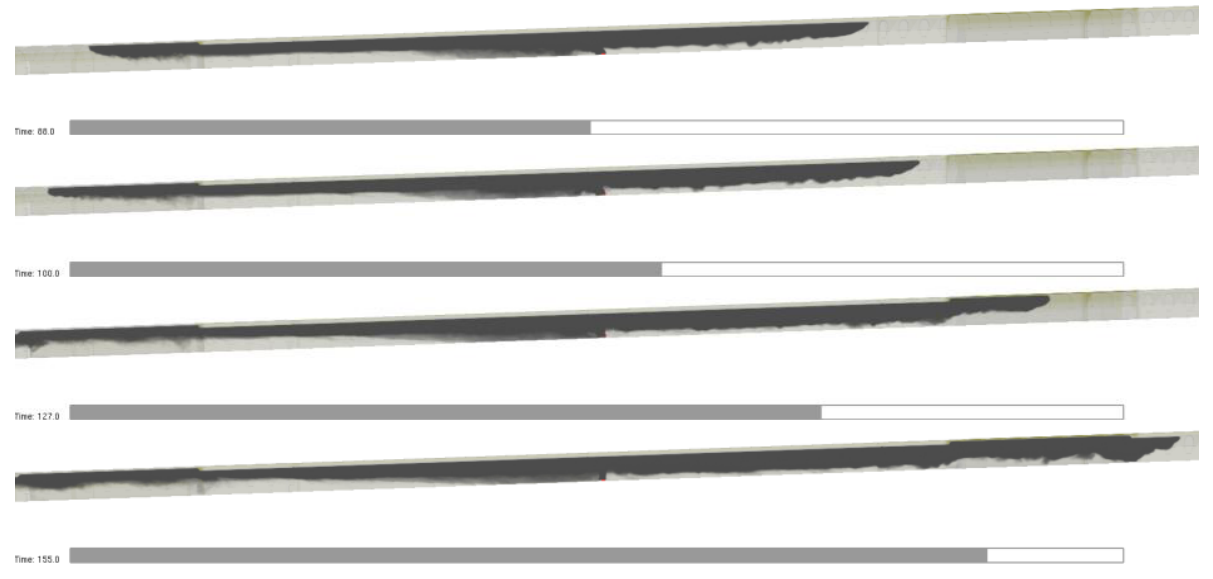

Fig. 2. Development of smoke at the $88^{\text {th }}, 100^{\text {th }}, 127^{\text {th }}$ and $155^{\text {th }}$ second of fire.

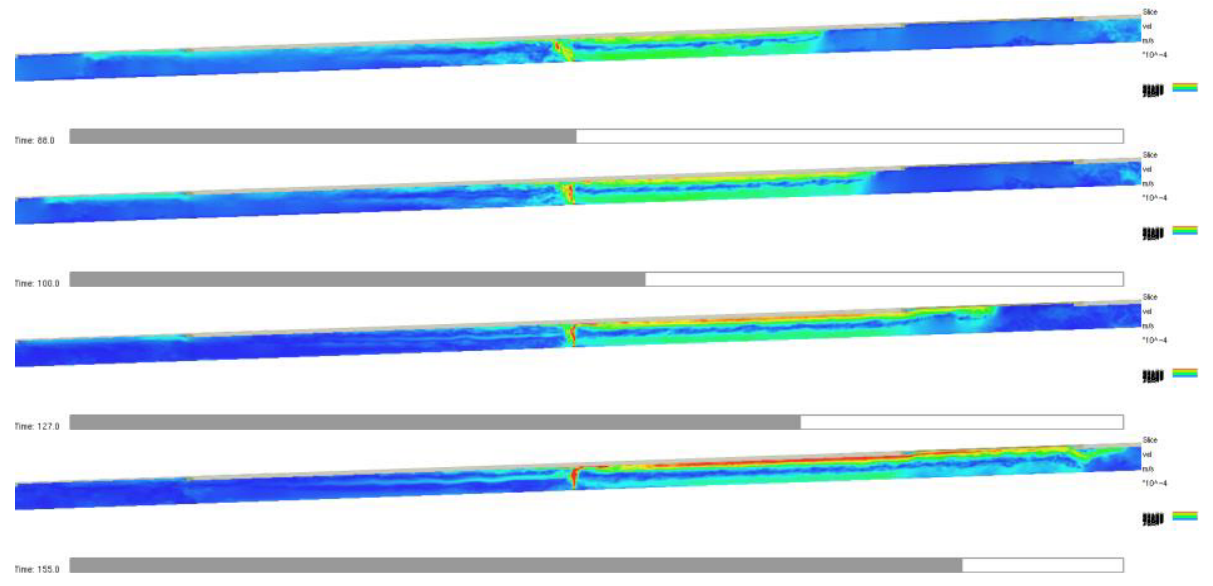

Fig. 3. Flow velocity at the $88^{\text {th }}, 100^{\text {th }}, 127^{\text {th }}$ and $155^{\text {th }}$ second of fire (red and blue colour represents the biggest and smallest values, respectively).

At the $88^{\text {th }}$ second of the fire, the tenable conditions are maintained at the left as well as at the right from the fire source. The corresponding vertical section of the flow velocity in the middle of the tunnel in Fig. 3 shows different tendency of air flow at the left and at the right from the fire source. At the right from the fire source, a marked counter-flow is formed. At the $100^{\text {th }}$ second of the fire, the smoke comes to the emergency lay-by located at the right from the fire source. The conditions are tenable both at the left and at the right from the fire source. At the right from the fire source the smoke spread in upper part of the 
tunnel tube faster to the right tunnel portal because of the impact of buoyancy force. At the same time creation of a lower counter-flow to the fire source can be observed which cools down the smoke layer (see Fig. 3).
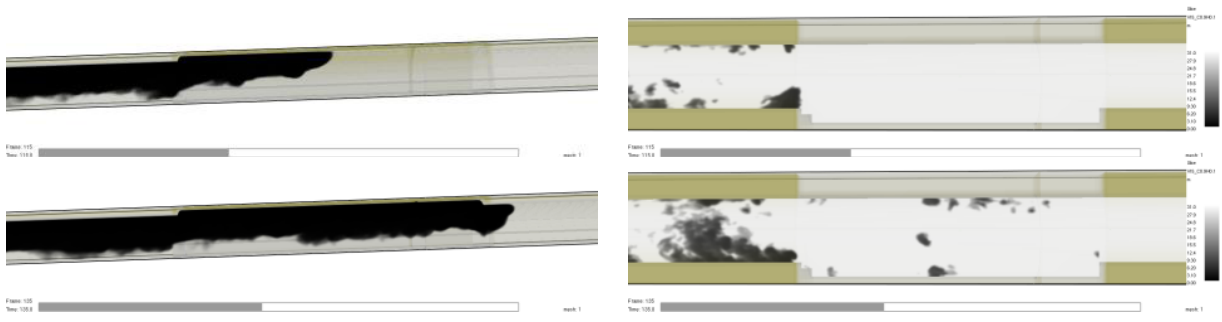

Fig. 4. Visibility decrease at the beginning of lay-by between 115th and 135th $\mathrm{s}$ of the fire caused by the spread of smoke layer through the tunnel tube with enlarged cross section into lay-by
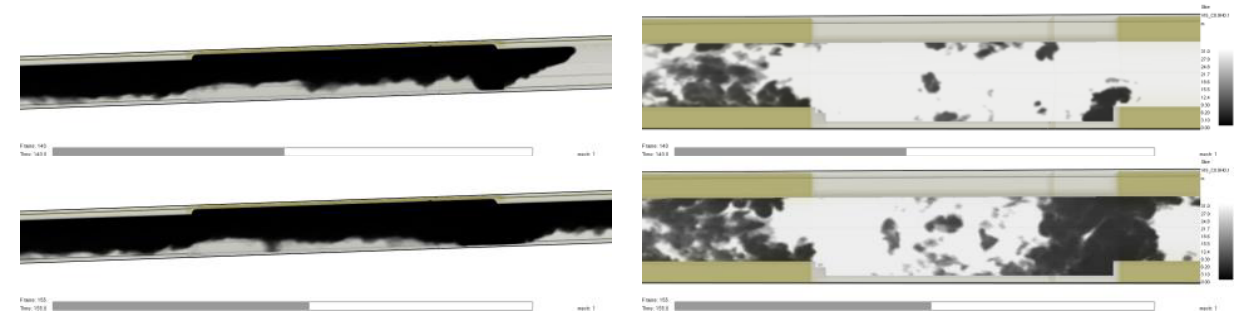

Fig. 5. Visibility decrease at the end of lay-by between 140th and 155th $\mathrm{s}$ of the fire caused by the spread of smoke layer from lay-by to tunnel tube with narrower cross section.

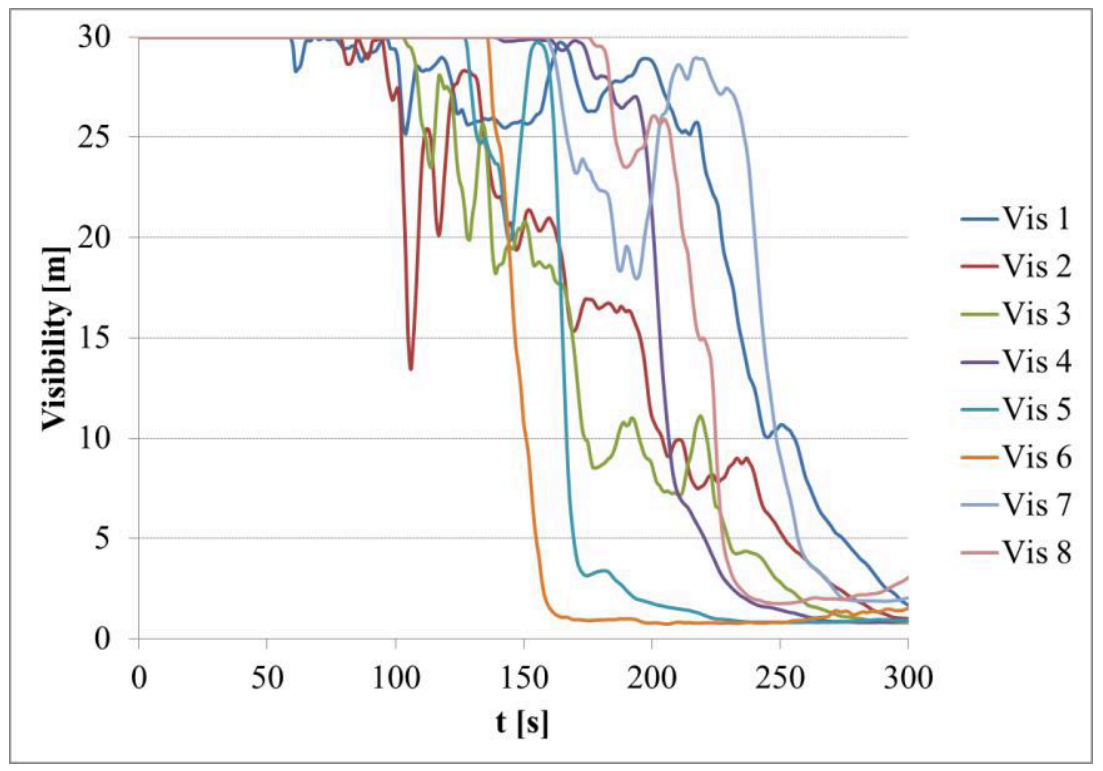

Fig. 6. Visibility at head level in eight selected points in the tunnel during the fire (the point are about $25 \mathrm{~m}$ far from each other at the right side from the fire source). 
At the $127^{\text {th }}$ second of the fire, the smoke came into the emergency lay-by at the right from the fire source and started to fall down creating safety risk. In the velocity section turbulences can be observed in the emergency lay-by. At the left from the fire source, the smoke stratification is maintained. At the $155^{\text {th }}$ second of the fire, the tenable conditions are at the left of the fire source. The conditions in front of the emergency lay-by at the right from the fire source are failing and the safety risk is formed at the end as well as behind the emergency lay-by because of cooling, air blast onto vertical obstruction and marked turbulence at the end of the emergency lay-by (see Fig. 3). As since the $182^{\text {nd }}$ second the air flow velocity to the fire source is increased, untenable conditions will emerge gradually people at the right and then at the left from the fire source. In the considered scenario two emergent places were originated at the right from the fire source (in front of the emergency lay-by and behind the emergency lay-by). In Figures 4 and 5, the breach of the smoke stratification at some places in the tunnel are illustrated. In Fig. 6, the decrease of visibility at selected places in the tunnel is shown.

\section{Conclusion}

In this paper some specific phenomena related to disruption of smoke stratification in the Polana highway tunnel are illustrated. The phenomena endanger the safe evacuation of people from the tunnel are illustrated. The simulation results indicate that the critical places of the tunnel are located in front of and behind the emergency lay-bys.

The authors would like to thank to P. Schmidt (National Highway Company, a.s.) and P. Pospisil (IP Engineering $\mathrm{GmbH}$ ) for providing us the information about technical specifications of the Polana highway tunnel. This work was supported by the Slovak Research and Development Agency APVV (project No. APVV-15-0340).

\section{References}

1. P. Weisenpacher, J. Glasa, L. Halada, L. Valasek, V. Sipkova, Parallel computer simulation of fire in road tunnel and people evacuation, Comput. Inform. 33(6): 12371268 (2014)

2. R.E. Greuer, Modeling the movement of smoke and the effect of ventilation systems in mine shaft fires. Fire Safety J. 9: 81-87 (1985).

3. Ch.D. Ang, G. Rein, J. Peiro, R. Harrison, Simulating longitudinal ventilation flows in long tunnels: Comparison of full CFD and multi-scale modelling approaches in FDS6, Tunnelling and Underground Space Technology. 52: 119-126 (2016)

4. D.F. Fletcher, J.H. Kent, Numerical simulations of smoke movement from a pool fire in a ventilated tunnel. Fire Safety J. 23: 305-325 (1994)

5. P.J. Woodburn, R.E. Britter, CFD Simulation of tunnel fire - part 2. Fire Safety J. 26: 63-90 (1996)

6. P.Z. Gao, S.L. Liu, W.K. Chow, N.K. Fong, Large eddy simulation for studying tunnel smoke ventilation. Tunnel. Undergr. Space Technol. 19: 577-586 (2004).

7. K. McGrattan, S. Hostikka, R. McDermott, J. Floyd, C. Weinschenk, K. Overholt, Fire Dynamics Simulator Technical Reference Guide, Validation, vol. 3, sixth ed. NIST and VTT Technical Research Centre of Finland (2014). 
8. K. McGrattan, S. Hostikka, R. McDermott, J. Floyd, C. Weinschenk, K. Overholt, Fire Dynamics Simulator, Technical Reference Guide (National Institute of Standards and Technology, Gaithersburg, Maryland, USA, and VTT Technical Research Centre of Finland, Espoo, Finland, sixth edition, 2017)

9. K. McGrattan, S. Hostikka, R. McDermott, J. Floyd, C. Weinschenk, K. Overholt, Fire Dynamics Simulator, User's Guide (National Institute of Standards and Technology, Gaithersburg, Maryland, USA, and VTT Technical Research Centre of Finland, Espoo, Finland, sixth edition, 2017

10. P. Weisenpacher, J. Glasa, L. Halada, Automobile interior fire and its spread to an adjacent vehicle: parallel simulation, Journal of Fire Sciences 34(4): 305-322 (2016)

11. P. Weisenpacher, J. Glasa, L. Halada, Parallel computation of smoke movement during a car park fire, Comput. Inform. 35(6): 1416-1437 (2016)

12. L. Halada, P. Weisenpacher, J. Glasa, Computer Modelling of Automobile Fires. Chapter 9. In: Advances in Modeling of Fluid Dynamics (LIU, Chaoqun, ed.). InTech Publisher, Rijeka, 203-228 (2012)

13. L. Valasek, J. Glasa, P. Weisenpacher, L. Halada, Impact of vehicles on smoke spread dynamics in the case of fire in road tunnel, J. of Physics: Conf. Ser. 574 (2015)

14. SIVVP - Slovak Infrastructure for High Performance Computing. Available from: http://www.sivvp.sk/, http://hpc.ui.savba.sk/

15. P. Danisovic, J. Sramek, E. Jancarikova, Special vocational training and education on tunnel traffic \& operation simulator, Proc 9th annual International Conference of Education, Research and Innovation, Seville, Spain, pp 997-1003.

16. E. Jancarikova, P. Danisovic, J. Sramek, Increase of road tunnels safety using Tunnel Traffic \& Operation Simulator, Proc 5th International Conference "Integration, Partnership and Innovation in Construction Science and Education", Moscow, Russia.

17. P. Danisovic, M. Razga, S. Sedivy, Road Tunnel Operation and Simulation, Procedia Engineering 111: 134-141 (2015)

18. Practice Note for Tenability Criteria in Building Fires (Society of Fire Safety, Engineers Australia, 2014)

19. D.A. Purser, Assessment of Hazards to Occupants from Smoke, Toxic Gases and Heat. In: DiNenno, P. J. (Ed.): The SFPE Handbook of Fire Protection Engineering. 4th Edition, National Fire Protection Association, Quincy, MA 02269, 2009, pp. 2-96 - 2193.

20. TP 12/2011 Road tunnels ventilation (in Slovak), Ministry of Transport and Construction of the Slovak Republic, 2011.

21. Guideline - Road tunnels ventilation (in Czech), Ministry of Transport of the Czech Republic, 2013.

22. http://ndsas12.cmsromboid.sk/prehlad-tunelov/44346s

23. http://www.sta-ita-aites.sk/index.php?page=tunely_vo_vystavbe

24. H. Ingason, Y.Z. Li, A. Lönnermark, Tunnel fire dynamics (Springer-Verlag, New York, 2015)

25. R.L. Alpert, Fire induced turbulent ceiling-jet. (Report no. 19722-2. Factory Mutual Research Corp., Norwood, 1971)

26. H.Z. You, G.M. Faeth, An investigation of fire plume impingement on a horizontal ceiling 2 - Impingement and ceiling-jet regions, Fire and Materials. 9 (1): 46-56 (1985) 